\title{
Polymorphisms in the GSTT1 and GSTM1 genes are associated with increased risk of preeclampsia in the Mexican mestizo population
}

A. Sandoval-Carrillo ${ }^{1}$, M. Aguilar-Duran ${ }^{1}$, F. Vázquez-Alaniz ${ }^{2}$, F.X. Castellanos-Juárez ${ }^{1}$, M. Barraza-Salas ${ }^{1}$, E. Sierra-Campos ${ }^{3}$, A. Téllez-Valencia ${ }^{4}$, O. La Llave-León ${ }^{1}$ and J.M. Salas-Pacheco ${ }^{1}$

\begin{abstract}
${ }^{1}$ Instituto de Investigación Científica, Universidad Juárez del Estado de Durango, Durango, México

${ }^{2}$ Hospital General de Durango, Secretaría de Salud, Durango, México

${ }^{3}$ Departamento de Bioquímica y Biología Molecular,

Facultad de Ciencias Químicas, Universidad Juárez del Estado de Durango, Durango, México

${ }^{4}$ Facultad de Medicina y Nutrición, Universidad Juárez del Estado de Durango, Durango, México
\end{abstract}

Corresponding author: J.M. Salas-Pacheco

E-mail: jsalas_pacheco@hotmail.com

Genet. Mol. Res. 13 (1): 2160-2165 (2014)

Received April 26, 2013

Accepted September 16, 2013

Published January 17, 2014

DOI http://dx.doi.org/10.4238/2014.January.17.3

\begin{abstract}
Preeclampsia is a pregnancy-specific disorder in humans and a major cause of maternal and neonatal morbidity and mortality. Increasing evidence suggests that oxidative stress plays an important role in the pathogenesis of preeclampsia. The aim of this study was to investigate the relationship between null alleles of the glutathione S-transferases (GST) M1 and T1 genes and the risk of preeclampsia. This case-control study involved 112 preeclamptic and 233 normoevolutive pregnant women. The null polymorphisms were
\end{abstract}


genotyped by multiplex polymerase chain reaction (PCR). Our results showed an increased risk of preeclampsia in patients with the GSTT1 null genotype [odds ratio $(\mathrm{OR})=2.21 ; 95 \%$ confidence interval $(\mathrm{CI})$ $=1.14-4.27 ; \mathrm{P}=0.018]$. Our data further showed that a combination of deletion genotypes of the GSTM1 and GSTT1 genes conferred an even higher risk of preeclampsia $(\mathrm{OR}=4.56,95 \% \mathrm{CI}=1.59-13.09$; $\mathrm{P}=0.005$ ). Our results provide the first evidence suggesting that a GSTT1 null polymorphism might be associated with preeclampsia in the Mexican mestizo population, and that this risk increases with the combination of both GSTT1 and GSTM1 null polymorphisms.

Key words: GSTM1; GSTT1; Preeclampsia

\section{INTRODUCTION}

Preeclampsia is a hypertensive multisystemic disorder unique to humans, which affects approximately $10 \%$ of all pregnancies with a slightly higher incidence in developing countries. Preeclampsia is a major cause of maternal deaths of obstetric cause and is responsible for high morbidity and fetal mortality (Aris et al., 2009). Preeclampsia is characterized by de novo hypertension (two blood pressure measurements $\geq 140 / 90 \mathrm{mmHg}$ ) and proteinuria ( $>300$ $\mathrm{mg} / 24 \mathrm{~h}$ ) that develops after 20 weeks of gestation in a formerly normotensive woman (Health Secretary, 2007). The pathophysiology is characterized by an abnormal vascular response to placentation that is associated with increased systemic vascular resistance, enhanced platelet aggregation, activation of the coagulation system, and endothelial cell dysfunction (Sibai et al., 2005).

Increasing evidence suggests that oxidative stress plays an important role in the pathogenesis of preeclampsia (Patil et al., 2009; Siddiqui et al., 2010). In this regard, superoxides and free radicals generated during pregnancy could attack lipids, proteins, and nucleic acids, resulting in damage to placental cells, tissues, and organs. In addition, maternal oxidative stress could initiate maternal vascular endothelial dysfunction and induce leukocyte activation (Orhan et al., 2003; Serdar et al., 2003).

One of the most important systems involved in the metabolism and detoxification of reactive oxygen, xenobiotics, and carcinogens, is that of glutathione S-transferases (GSTs), which catalyze the nucleophilic addition of glutathione to electrophilic centers of a wide range of substances such as aliphatic and heterocyclic radicals, epoxides, or arene oxides (Seidegard and Ekstrom, 1997).

Four families of cytosolic soluble GSTs, alpha, mu, pi, and theta, with each class consisting of one or more isoenzymes and a wide variety of substrate specificities, are known in humans, and all have been found to be genetically polymorphic. Deletion polymorphisms have been found in the GSTM1 gene (GSTM1) and in the GSTT1 gene (GSTT1) (Beckett and Hayes, 1993; Hayes and Pulford, 1995). The percentage of individuals who do not express the GSTM1 enzyme due to a homozygous gene deletion is higher in Caucasians and Asians than in Africans (Bailey et al., 1998; Roth et al., 2000). Approximately $60 \%$ of Asians, $40 \%$ of Africans, and $20 \%$ of Caucasians do not express the GSTT1 enzyme (Strange and Fryer, 1999). 
In the present study, we aimed to investigate the relationship between null polymorphisms in GSTT1 and GSTM1 and the risk of preeclampsia.

\section{MATERIAL AND METHODS}

\section{Selection of patients}

This case-control study was approved by the Investigation Ethical Committee in the Hospital General of the Ministry of Health of Durango, Mexico in accordance with the Code of Ethics of the Declaration of Helsinki. We recruited 112 women diagnosed with preeclampsia and 233 normotensive pregnant women.

\section{Genotyping}

The GSTT1 and GSTM1 null polymorphisms were analyzed using multiplex polymerase chain reaction (PCR). GSTM1 and GSTT1 were amplified using the following primers: 5'-GAACTCCCTGAAAAGCTAAAGC-3' and 5'-GTTGGGCTCAAATATACGGTGG-3' for GSTM1 and 5'-TTCCTTACTGGTCCTCACATCTC-3' and 5'-TCACCGGATCATGGCCAGCA$3^{\prime}$ for GSTT1. As an internal control, the $\beta$-globin gene was co-amplified using the primers 5'-ACACAACTGTGTTCACTAGC-3' and 5'-CAACTTCATCCACGTTCACC-3'. Amplified DNA fragments were resolved by $3 \%$ agarose gel electrophoresis yielding $480 \mathrm{bp}, 312 \mathrm{bp}$, and 113 bp for GSTT1, GSTM1, and $\beta$-globin, respectively.

\section{Statistical analysis}

Independent sample Student's $t$-tests were performed using the SPSS software (version 15.0; SPSS Inc., Chicago, IL, USA). Odds ratios (ORs) as estimates of relative risk of the disease were calculated with $95 \%$ confidence intervals (95\%CIs). The ORs were adjusted for variations in age and weeks of pregnancy by means of a multivariate logistic regression model.

\section{RESULTS}

Table 1 shows the clinical characteristics for cases and controls. Variables that exhibited a significant difference between groups were weeks of pregnancy and systolic and diastolic blood pressure $(\mathrm{P}<0.05)$. Although a significant difference between cases and controls was found with respect to weeks of pregnancy, this difference is not clinically relevant.

Table 1. Clinical characteristics for cases and controls.
\begin{tabular}{lccc} 
& & \\
\hline Clinical features & Cases $(\mathrm{N}=112)$ & Controls $(\mathrm{N}=233)$ & P value \\
\hline Age (years) & $24.42(7.32)^{\mathrm{a}}$ & $24.28(6.92)$ & $0.861^{\mathrm{b}}$ \\
Weeks of pregnancy & $35.16(5.48)^{\mathrm{a}}$ & $37.51(4.14)$ & $0.0001^{\mathrm{b}}$ \\
Systolic BP $(\mathrm{mmHg})$ & $156.12(17.81)^{\mathrm{a}}$ & $112.17(11.64)$ & $0.0001^{\mathrm{b}}$ \\
Diastolic BP $(\mathrm{mmHg})$ & $100.22(10.68)^{\mathrm{a}}$ & $70.57(10.03)$ & $0.0001^{\mathrm{b}}$ \\
\hline a Media \pm Standard deviation; ${ }^{\mathrm{b}}$ Independent sample $t$ - test.
\end{tabular}


With regard to GSTM1 and GSTT1 null polymorphisms, we found significant differences in null genotypes between cases and controls (Table 2). For GSTM1 polymorphisms, the frequencies for the null genotype were $44.64 \%$ and $44.2 \%$ for cases and controls, respectively, whereas for GSTT1 polymorphisms, the frequencies for the null genotype were $18.75 \%$ and $10.3 \%$ for cases and controls, respectively. The GSTT1 null polymorphism showed a significant risk of preeclampsia (adjusted $\mathrm{OR}=2.21 ; 95 \% \mathrm{CI}=1.14-4.27 ; \mathrm{P}=0.018$, Table 2).

Table 2. Distributions of GSTM1, GSTT1, double GST genotypes and risk estimation between cases and controls.

\begin{tabular}{|c|c|c|c|c|c|}
\hline Genotype & Cases $(\mathrm{N}=112)$ & Controls $(\mathrm{N}=233)$ & OR & $95 \%$ CI & $P$ value \\
\hline \multicolumn{6}{|l|}{ GSTM1 } \\
\hline Present & $62(55.35 \%)$ & $130(55.79 \%)$ & 1 & (referent) & \\
\hline Null & $50(44.64 \%)$ & $103(44.20 \%)$ & 0.925 & $0.577-1.484$ & 0.747 \\
\hline \multicolumn{6}{|l|}{ GSTT1 } \\
\hline Present & $91(81.25 \%)$ & 209 (89.69\%) & 1 & (referent) & \\
\hline Null & $21(18.75 \%)$ & $24(10.30 \%)$ & 2.21 & $1.14-4.27$ & 0.018 \\
\hline \multicolumn{6}{|c|}{ Double genotype } \\
\hline Both present & $54(48.21 \%)$ & $112(48.06 \%)$ & 1 & (referent) & \\
\hline Either null & $45(40.17 \%)$ & $115(49.35 \%)$ & 0.76 & $0.46-1.25$ & 0.288 \\
\hline Both null & $13(11.60 \%)$ & $6(2.57 \%)$ & 4.56 & $1.59-13.09$ & 0.005 \\
\hline
\end{tabular}

Three practical genetic combinations of GSTM1 and GSTT1 genotypes were evaluated: 1) carriers of functional genes (GSTM1 and GSTT1), 2) carriers of either GSTM1 or GSTT1 as functional genotypes, and 3) carriers of both null genotypes. Approximately $11.6 \%$ of cases and $2.57 \%$ of controls carried both null genotypes of GSTM1 and GSTT1, which increased the risk of preeclampsia by approximately 5 -fold $(\mathrm{OR}=4.56 ; 95 \% \mathrm{CI}=1.59-13.09 ; \mathrm{P}$ $=0.005$, Table 2).

\section{DISCUSSION}

Although the exact etiology and pathogenesis of preeclampsia remain unknown, there is substantial evidence that maternal endothelial cell dysfunction and damage lead to placental hypoperfusion and ischemia. Oxidative stress has been proposed as an underlying mechanism that contributes to the endothelial dysfunction associated with preeclampsia.

GST is a large family of anti-oxidant enzymes. Specifically, GSTT1 and GSTM1 have been associated with various pathologies including oral cancer, cervical neoplasia, breast cancer, glaucoma, hepatocellular carcinoma, and type 2 diabetes (Gao et al., 2011; Zhang et al., 2011; Song et al., 2012; Sohail et al., 2013; Yi et al., 2013; Yu et al., 2013). Moreover, several studies were previously conducted to assess the role of GST genes in preeclampsia (Zusterzeel et al., 2000; Cetin et al., 2005; Kim et al., 2005; Zhang et al., 2008; Atalay et al., 2012; Saadat et al., 2012), but to date, only a deletion of the GSTP1 gene has been associated with the pathology (Zusterzeel et al., 2000).

This study is the first to report an association between GSTM1 and GSTT1 null polymorphisms and susceptibility to preeclampsia in the Mexican mestizo population. Pérez-Morales et al. (2008) reported that the frequencies of GSTM1, GSTT1, and double GSTT1/GSTM1 null polymorphisms were $0.335,0.121$, and 0.023 , respectively, in a Mexican mestizo population. We found very similar results for our control group.

The results of the current study are the first to demonstrate an increased risk of pre- 
eclampsia in women with the GSTT1 null genotype $(\mathrm{OR}=2.21 ; 95 \% \mathrm{CI}=1.14-4.27 ; \mathrm{P}=$ $0.018)$. Furthermore, this risk was increased with the combination of both null polymorphisms $(\mathrm{OR}=4.56 ; 95 \% \mathrm{CI}=1.59-13.09 ; \mathrm{P}=0.005)$. The differences between our results and those previously reported may be explained on the basis of the great genetic heterogeneity in the Mexican mestizo population compared with Caucasian or Asian populations. These differences may be observed even between subpopulations from different regions throughout Mexico (Silva-Zolezzi et al., 2009). In conclusion, this is the first study to suggest that GSTT1 null polymorphisms, as well as GSTT1/GSTM1 double null polymorphisms, are associated with preeclampsia. Therefore, these polymorphisms might be a risk factor for this disorder in the Mexican mestizo population.

\section{ACKNOWLEDGMENTS}

Research supported by grant (\#2011-01-161553) from CONACYT/México to J.M. Salas-Pacheco. A. Sandoval-Carrillo was supported by a doctoral fellowship from CONACYT. We thank I. Antuna-Salcido, V. Chávez-Villa, and J. Drumond-López for excellent technical assistance.

\section{REFERENCES}

Aris A, Benali S, Ouellet A, Moutquin JM, et al. (2009). Potential biomarkers of preeclampsia: inverse correlation between hydrogen peroxide and nitric oxide early in maternal circulation and at term in placenta of women with preeclampsia. Placenta 30: 342-347.

Atalay MA, Ozerkan K, Karkucak M, Yakut T, et al. (2012). Polymorphisms in angiotensin-converting enzyme and glutathione s-transferase genes in Turkish population and risk for preeclampsia. Clin. Exp. Obstet. Gynecol. 39: 466-469.

Bailey LR, Roodi N, Verrier CS, Yee CJ, et al. (1998). Breast cancer and CYPIA1, GSTM1, and GSTT1 polymorphisms: evidence of a lack of association in Caucasians and African Americans. Cancer Res. 58: 65-70.

Beckett GJ and Hayes JD (1993). Glutathione S-transferases: biomedical applications. Adv. Clin. Chem. 30: 281-380.

Cetin M, Pinarbasi E, Percin FE, Akgun E, et al. (2005). No association of polymorphisms in the glutathione S-transferase genes with pre-eclampsia, eclampsia and HELLP syndrome in a Turkish population. J. Obstet. Gynaecol. Res. 31: 236-241.

Gao LB, Pan XM, Li LJ, Liang WB, et al. (2011). Null genotypes of GSTM1 and GSTT1 contribute to risk of cervical neoplasia: an evidence-based meta-analysis. PLoS One 6: e20157.

Hayes JD and Pulford DJ (1995). The glutathione S-transferase supergene family: regulation of GST and the contribution of the isoenzymes to cancer chemoprotection and drug resistance. Crit. Rev. Biochem. Mol. Biol. 30: 445-600.

Health Secretary (2007). Technical Guidelines for Prevention, Diagnosis and Management of Preeclampsia/Eclampsia. Secretaria de Salud, México DF.

Kim YJ, Park HS, Park MH, Suh SH, et al. (2005). Oxidative stress-related gene polymorphism and the risk of preeclampsia. Eur. J. Obstet. Gynecol. Reprod. Biol. 119: 42-46.

Orhan H, Onderoglu L, Yucel A and Sahin G (2003). Circulating biomarkers of oxidative stress in complicated pregnancies. Arch. Gynecol. Obstet. 267: 189-195.

Patil SB, Kodliwadmath MV and Kodliwadmath M (2009). Lipid peroxidation and antioxidant activity in complicated pregnancies. Clin. Exp. Obstet. Gynecol. 36: 110-112.

Pérez-Morales R, Castro-Hernandez C, Gonsebatt ME and Rubio J (2008). Polymorphism of CYP1A1*2C, GSTM1*0, and GSTT1*0 in a Mexican Mestizo population: a similitude analysis. Hum. Biol. 80: 457-465.

Roth MJ, Dawsey SM, Wang G, Tangrea JA, et al. (2000). Association between GSTM1*0 and squamous dysplasia of the esophagus in the high risk region of Linxian, China. Cancer Lett. 156: 73-81.

Saadat M, Anvar Z, Namavar-Jahromi B and Saadat I (2012). Genetic polymorphisms of glutathione S-transferase Z1 (GSTZ1) and susceptibility to preeclampsia. Mol. Biol. Rep. 39: 8995-8998.

Seidegard J and Ekstrom G (1997). The role of human glutathione transferases and epoxide hydrolases in the metabolism 
of xenobiotics. Environ. Health Perspect. 105 (Suppl 4): 791-799.

Serdar Z, Gur E, Colakoethullary M, Develioethlu O, et al. (2003). Lipid and protein oxidation and antioxidant function in women with mild and severe preeclampsia. Arch. Gynecol. Obstet. 268: 19-25.

Sibai B, Dekker G and Kupferminc M (2005). Pre-eclampsia. Lancet 365: 785-799.

Siddiqui IA, Jaleel A, Tamimi W and Al Kadri HM (2010). Role of oxidative stress in the pathogenesis of preeclampsia. Arch. Gynecol. Obstet. 282: 469-474.

Silva-Zolezzi I, Hidalgo-Miranda A, Estrada-Gil J, Fernandez-Lopez JC, et al. (2009). Analysis of genomic diversity in Mexican Mestizo populations to develop genomic medicine in Mexico. Proc. Natl. Acad. Sci. U. S. A. 106: 86118616.

Sohail A, Kanwal N, Ali M, Sadia S, et al. (2013). Effects of glutathione-S-transferase polymorphisms on the risk of breast cancer: a population-based case-control study in Pakistan. Environ. Toxicol. Pharmacol. 35: 143-153.

Song K, Yi J, Shen X and Cai Y (2012). Genetic polymorphisms of glutathione S-transferase genes GSTM1, GSTT1 and risk of hepatocellular carcinoma. PLoS One 7: e48924.

Strange RC and Fryer AA (1999). The glutathione S-transferases: influence of polymorphism on cancer susceptibility. IARC Sci. Publ. 231-249.

Yi R, Liu B and Dong Q (2013). Assessment of the association between GSTM1 null genotype and risk of type 2 diabetes. Mol. Biol. Rep. 40: 3961-3967.

Yu Y, Weng Y, Guo J, Chen G, et al. (2013). Association of glutathione S transferases polymorphisms with glaucoma: a meta-analysis. PLoS One 8: e54037.

Zhang J, Masciocchi M, Lewis D, Sun W, et al. (2008). Placental anti-oxidant gene polymorphisms, enzyme activity, and oxidative stress in preeclampsia. Placenta 29: 439-443.

Zhang ZJ, Hao K, Shi R, Zhao G, et al. (2011). Glutathione S-transferase M1 (GSTM1) and glutathione S-transferase T1 (GSTT1) null polymorphisms, smoking, and their interaction in oral cancer: a HuGE review and meta-analysis. Am. J. Epidemiol. 173: 847-857.

Zusterzeel PL, Visser W, Peters WH, Merkus HW, et al. (2000). Polymorphism in the glutathione S-transferase P1 gene and risk for preeclampsia. Obstet. Gynecol. 96: 50-54. 